\title{
Safety and Efficacy of Transvenous Embolization of Ruptured Brain Arteriovenous Malformations as a Last Resort: A Prospective Single-Arm Study
}

\author{
(D)Y. He, (D) Y. Ding, (DW. Bai, (D)T. Li, (D)F.K. Hui, (D)W.-J. Jiang, and (D). Xue
}

\begin{abstract}
BACKGROUND AND PURPOSE: The efficacy and safety of transvenous embolization for brain arteriovenous malformations remains unclear, given the very limited number of cases reported. This prospective study was performed to assess this technique in ruptured AVMs.
\end{abstract}

\begin{abstract}
MATERIALS AND METHODS: Twenty-one consecutive patients with ruptured brain AVMs who underwent transvenous embolization were prospectively followed between November 2016 and November 2018. The Spetzler-Martin grade was I in 3 AVMs (14.3\%), II in four (19.0\%), III in eleven (52.4\%), and IV in three (14.3\%). The complete AVM occlusion rate was calculated from 6-month follow-up DSA images. Occurrence of hemorrhage and infarction after embolization was evaluated using CT and MR imaging within 1 month after the operation. The mRS was used to assess the functional outcomes.
\end{abstract}

RESULTS: Complete AVM nidus obliteration was shown in 16 (84\%) of 19 patients with technically feasible AVMs immediately after embolization. One (5\%) patient with a small residual nidus after treatment showed complete obliteration at 13-month follow-up. There were 5 hemorrhages and 1 infarction; 4 patients' symptoms improved gradually. The percentage of cases with mRS $\leq 2$ rose from $57.1 \%$ (12/21) before embolization to $66.7 \%(14 / 21)$ at 1-month follow-up. Both the morbidity and mortality rates were $4.8 \%(1 / 21)$.

CONCLUSIONS: Transvenous embolization can be performed only in highly selected hemorrhagic brain AVMs with high complete obliteration rates, improved functional outcomes, and acceptable morbidity and mortality rates, but it should not be considered as a first-line treatment.

B rain arteriovenous malformations are characterized by an intervening plexus of abnormal vessels (nidus) between feeding arteries and draining veins. The most common presentations of AVMs include hemorrhages, seizures, headaches, and

Received May 17, 2019; accepted after revision July 23.

From the Department of Interventional Neuroradiology (Y.H., W.B., T.L., J.X.), Henan Provincial People's Hospital, Zhengzhou University People's Hospital, Henan University People's Hospital, and Henan Provincial Neurointerventional Engineering Research Center, Zhengzhou, China; Department of Radiology (Y.D.), Mayo Clinic, Rochester, Minnesota; Department of Radiology (F.K.H.), Johns Hopkins Hospital, Baltimore, Maryland; and Department of Vascular Neurosurgery (W.-J.J.), the PLA Rocket Force General Hospital, Beijing, China.

Y. He, Y. Ding, and W. Bai contributed equally to this work.

The study was funded by the National Natural Science Foundation of China (No. 81601583), the Scientific and Technological Project (No. 2018020424), and Aboard Research Project (2016054) of Henan Provincial Health Commission.

Please address correspondence to Tianxiao Li, MD, Department of Interventional Neuroradiology, Henan Provincial People's Hospital, Zhengzhou University and Henan University, No. 7, Weiwu Rd, Zhengzhou, China; e-mail:

dr.litianxiao@henu.edu.cn

- Indicates open access to non-subscribers at www.ajnr.org

$\checkmark$ Indicates article with supplemental on-line video.

http://dx.doi.org/10.3174/ajnr.A6197 progressive neurologic deficits due to chronic vascular steal. ${ }^{1}$ Hemorrhage can occur because of an inherent lack of normal smooth-muscle properties in the vascular architecture of AVMs. A first hemorrhagic event is associated with an increased risk of a new bleeding. Morbidity of AVM hemorrhage is estimated to be between $13 \%$ and $50 \%$, and the mortality rate after intracranial hemorrhage from AVM rupture ranges from $12 \%$ to $67 \%{ }^{2}$

Treatment strategies (microsurgery, radiosurgery, and endovascular embolization) are chosen on the basis of angioarchitecture, location, and presentation of AVMs. ${ }^{3,4}$ Elimination of hemorrhage risk by extirpation or endoluminal closure of the nidus remains the primary goal of AVM treatment. Surgical resection of an AVM can be challenging in deep, inaccessible locations and eloquent areas. Radiosurgery may not be ideal in hemorrhagic AVMs as the first choice because of the long latency between treatment and AVM involution. Endovascular embolization through arterial routes may not be curative for AVMs in many situations, especially in cases with indirect feeders and extreme vessel tortuosity. ${ }^{5}$ Transvenous embolization can overcome these disadvantages. ${ }^{6-14}$ Current indications for transvenous embolization of AVMs include 
Table 1: Baseline characteristics of the 21 patients in this study

\begin{tabular}{lc}
\hline \multicolumn{1}{c}{ Variable } & Value \\
\hline Age (yr) & \\
Mean & 29.9 \\
Median & 29 \\
Range & $8-59$ \\
SD & 17.0 \\
Sex (No.) (\%) & \\
Male & $14(66.7)$ \\
Female & $7(33.3)$ \\
mRS before embolization (No.) (\%) & \\
0-2 & $12(57.1)$ \\
3-5 & $9(42.9)$ \\
Location (No.) (\%) & $18(85.7)$ \\
Deep & $3(14.3)$ \\
Superficial & $12(57.1)$ \\
Size (No.) (\%) & $9(42.9)$ \\
S3 cm & $15(71.4)$ \\
>3 cm & $6(28.6)$ \\
Eloquent (No.) (\%) & \\
Yes & $11(52.4)$ \\
No & $9(42.9)$ \\
Venous pattern (No.) (\%) & $1(4.8)$ \\
Superficial & $20(95.2)$ \\
Deep & $1(4.8)$ \\
Deep (main) + superficial & \\
No. of veins (\%) & $9(42.9)$ \\
Single & $4(19.0)$ \\
Multiple & $2(9.5)$ \\
Angioarchitecture (No.) (\%) & \\
Aneurysms in the feeding artery or intranidus \\
Venous stenosis & $3(14.3)$ \\
Localized venous ectasia & $4(19.0)$ \\
Spetzler-Martin grade (No.) (\%) & $11(52.4)$ \\
I & $3(14.3)$ \\
II & $0(0)$ \\
III & \\
IV & \\
V & \\
\hline
\end{tabular}

deep location, unfavorable arterial access, a small nidus, and a single draining vein. ${ }^{6-14}$ Because there are only a limited number of cases reported using this approach, the effectiveness and safety remain unclear. In this study, we tried to further validate this method.

\section{MATERIALS AND METHODS}

The Medical Ethics Committee of Henan Provincial People's Hospital approved this study. Key inclusion criteria were as follows: 1) patients with a ruptured brain AVM;2) patients not suitable for intra-arterial embolization due to the absence of arterial access, narrow arterial feeders, extremely tortuous course, too many feeders, and so forth; and 3) patients in whom lesions were not amenable to surgery or radiosurgery or patients who refused to undergo surgery or radiosurgery (AVMs not amendable to surgery or radiosurgery are defined as cases with modified Spetzler-Martin grades of III+, IV, and V based on modification of the Spetzler-Martin scale ${ }^{15}$ and those with scores of $>1.5$ based on Pollock-Flickinger grading scale, ${ }^{16}$ which are proved have high rates of iatrogenic complications); and 4) patients with
Table 2: Safety and efficacy outcomes

\begin{tabular}{lc}
\hline \multicolumn{1}{c}{ Variable } & Value \\
\hline Procedure & 21 \\
Patients (No.) & $19(90.5 \%)$ \\
Patients with technically feasible AVMs (No.) (\%) & $6(28.6)$ \\
Procedure-related complications (No.) (\%) & $4(19.0)$ \\
Transient & $0(0)$ \\
Permanent, nondisabling & $1(4.8)$ \\
Permanent, disabling & $1(4.8)$ \\
Death & $0(0)$ \\
Non-neurologic & \\
Follow-up & $16(84.2)$ \\
Immediate obliteration after procedure (No.) (\%) & $16(76.2)$ \\
In 19 patients with technically feasible AVMs & 14 \\
In all 21 patients & $5.5(3-15)$ \\
Imaging follow-up of patients (No.) & $13(92.9)$ \\
Follow-up time (median) (range) & $1(7.1)$ \\
Obliteration at follow-up (No.) (\%) & $0(0)$ \\
Stable & 21 \\
Recanalization & 6 \\
Clinical follow-up of patients within 1 mo (No.) & 6 \\
Events & 0 \\
Stroke & 20 \\
Others & $15(2-26)$ \\
Clinical follow-up of patients beyond 1 mo (No.) & 1 \\
The latest follow-up time (median) (range) & 1 \\
Events (No.) & 0 \\
Epilepsy & 19 \\
Others & 1 \\
The latest mRS & 0 \\
0-2 & \\
3-5 & \\
6 & \\
\hline & \\
\hline & \\
\hline
\end{tabular}

favorable venous angioarchitecture and a single main draining vein.

Key exclusion criteria were as follows: 1) multiple AVMs, 2) patients with $\geq 2$ main draining veins, 3 ) a history of severe allergies to contrast or nonadhesive embolic agents, and 4) uncontrolled active bleeding.

Twenty-one consecutive patients with ruptured brain AVMs underwent transvenous embolization between November 2016 and November 2018. Thirteen patients experienced brain AVM ruptures with intracranial hematoma and intraventricular hemorrhage, 6 patients had intracranial hematoma without intraventricular involvement, 1 patient had subarachnoid hemorrhage, and another one had intraventricular hemorrhage. The mean AVM size was $2.76 \pm 1.24 \mathrm{~cm}$, ranging from 1.2 to $5.5 \mathrm{~cm}$. A summary of patient characteristics is shown in Table 1 .

All the embolization procedures were performed with the patient under general anesthesia. A $6 \mathrm{~F}$ sheath was placed in the internal jugular vein followed by a $6 \mathrm{~F}$ guiding catheter, which was advanced to the main draining vein of the brain AVMs. One or 2 microcatheters (Marathon, Covidien, Irvine, California; Apollo, Covidien; Echelon, Covidien; or Headway DUO, MicroVention, Tustin, California) were placed as close as possible to the nidus of the AVMs. A vascular sheath was placed in the right femoral artery followed by guide catheter placement though which a microcatheter was advanced into the feeding artery of the AVMs. Arterial inflow of the feeding 


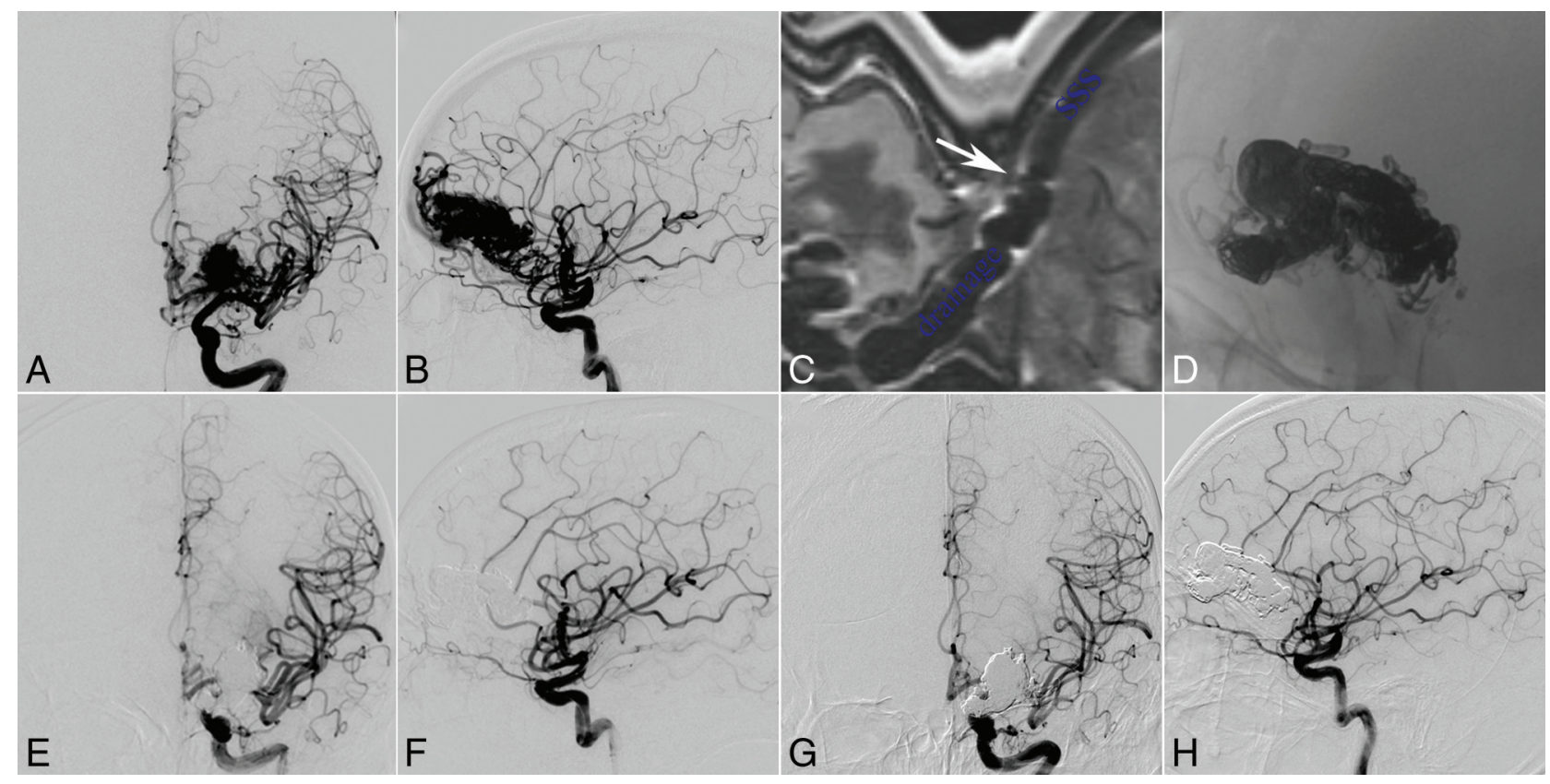

FIG 1. A 31-year-old man with intraparenchymal hemorrhage. Selective DSA of the left ICA (anteroposterior $[A]$ and lateral $[B]$ views) demonstrates that the AVM located at the frontal lobe is fed by the branches and perforators of anterior cerebral artery, MCA, and ICA and drains a single venous outlet via the cortical vein to the superior sagittal sinus (SSS). The high-resolution MR imaging shows that there is no severe stenosis or valvelike chordae in the connection part of the draining vein and superior sagittal sinus ( $C$, white arrow). The nidus cast is through the transvenous embolization ( $D$, unsubtracted image of the DSA), and the AVM is completely angiographically obliterated at the end of the operation (anteroposterior $[E]$ and lateral $[F]$ views) and at the 5-month follow-up (anteroposterior [G] and lateral $[H]$ views).

artery was reduced by transarterial coil or liquid embolization or balloon inflation. Transvenous embolization was initiated by injecting ethylene-vinyl alcohol copolymer (Onyx; Covidien) into the nidus through the venous access route. Transvenous partial coiling in the draining vein through 1 microcatheter (known as the transvenous pressure cooker technique) was used to prevent reflux of Onyx. ${ }^{17-19}$ At the completion of the procedure, the microcatheter injecting Onyx was cut at the level of the jugular sheath. ${ }^{14}$

Preoperative baseline functional status was determined using the mRS score. The same evaluation was performed on postoperative days 2, 7, and 30 and at 3,6, and 12 months. Occlusion of the AVM nidus was categorized as complete (no residual nidus) and near-complete obliteration (residual nidus of $<3 \mathrm{~mm}$ in diameter). Comparison of the degree of occlusion was classified as progressive, stable, or recanalized.

Procedural safety was evaluated by assessing the periprocedural complications occurring within 1 month after embolization. ${ }^{20}$ Any deficit that resolved within the first 30 days was characterized as transient. Any deficit that persisted beyond 30 days was considered permanent. An mRS score of $\leq 2$ indicated a nondisabling deficit. An $m R S$ score of $\geq 3$ indicated a disabling deficit. Periprocedural-related death was defined as any death occurring within 30 days after the procedure.

\section{Statistical Analysis}

Categoric variables are presented as numbers and percentages, and continuous variables are presented as mean and SD. A 2sided $P$ value $<.05$ was considered significant.

\section{RESULTS}

\section{Procedural/Technical Specifications}

The median time between hemorrhage and transvenous treatment was 47 days (range, 9-164 days). The procedure was technically feasible in $19(90.5 \%)$ cases (Table 2). There was failure of microcatheter placement into the draining vein via the nidus in 2 cases.

For the 19 embolization procedures, access included the straight sinus in 9 cases, the cortical veins via the superior sagittal sinus in 6 cases, and the cortical veins via the transverse sinus in 4 cases.

The transvenous pressure cooker technique and Onyx injection were accomplished using 1 microcatheter in 3 patients and 2 microcatheters in 16 patients. The microcatheters for Onyx injection were retained in all patients except one.

The mean procedural time of all 21 patients from puncture onset to puncture closing was $251.6 \pm 73.1$ minutes. The mean volume of Onyx used for embolization was $3.79 \pm 3.30 \mathrm{~mL}$ (range, $0-13 \mathrm{~mL}$ ).

\section{AVM Nidus Obliteration}

Immediately after the procedure, complete obliteration was achieved in 16 cases (Table 2), with an obliteration rate of $84.2 \%$ in the 19 technically feasible cases and $76.2 \%$ in all 21 cases. A postoperative small residual nidus was present in 3 patients after transvenous embolization. Follow-up angiography was performed from 1 to 15 months after embolization. Stable obliteration was confirmed in 18 patients. No recurrence was noted (Fig 1). One AVM located in the parietal lobe and basal ganglia showed progressive occlusion (Fig 2). 


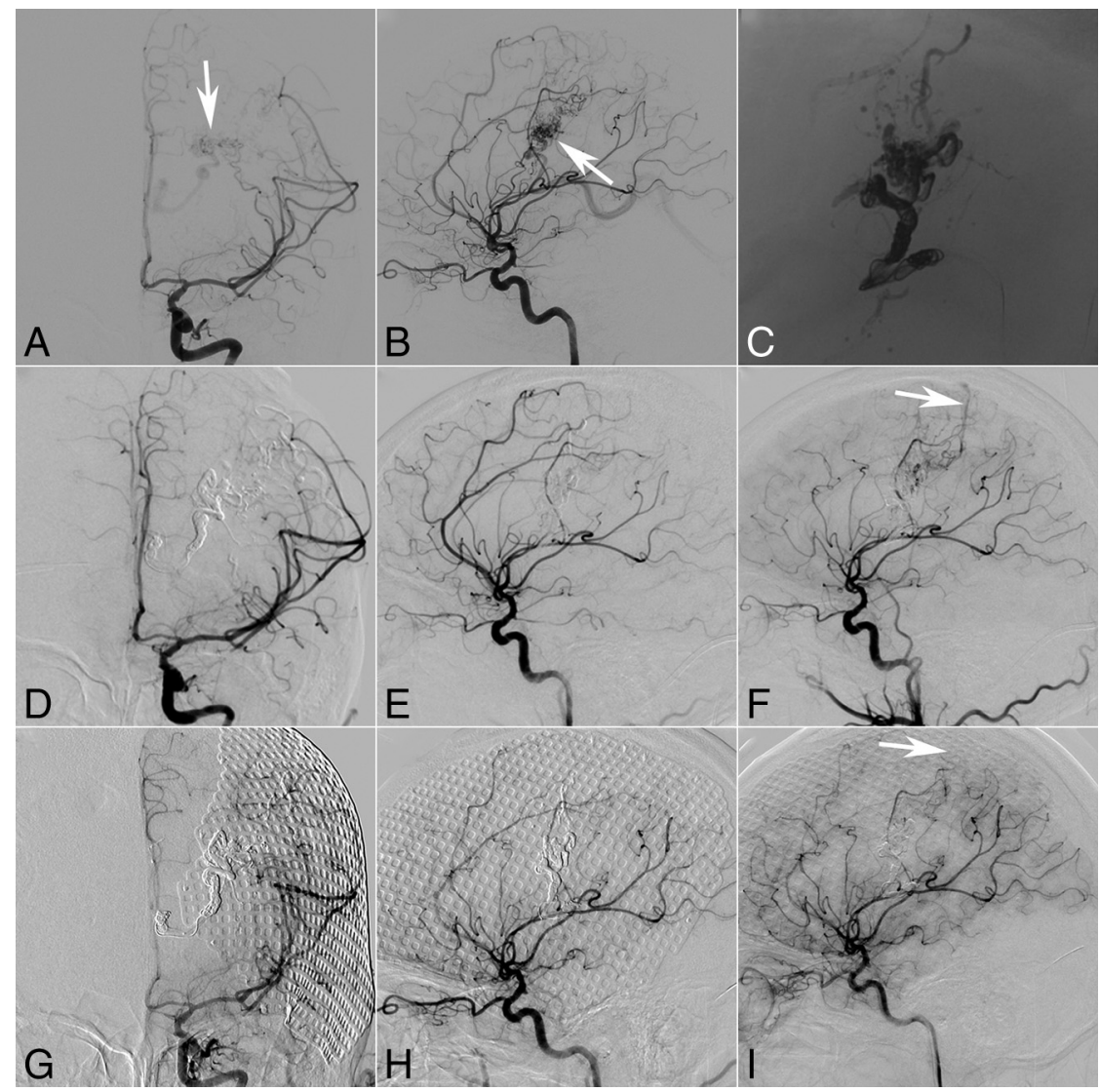

FIG 2. A 28-year-old man with intraparenchymal and intraventricular hemorrhage. Ventriculostomy, decompressive craniectomy, and transarterial embolization were performed at the local hospital. Three months later, the selective DSA of the left ICA (anteroposterior [A] and lateral $[B]$ views, both white arrows referring to the nidus) demonstrates that the parietal lobe and basal ganglia arteriovenous malformation are fed by the branches of the MCA and drain a single venous outlet via the deep vein to the straight sinus. The nidus cast was through transvenous embolization (C, unsubtracted image of the DSA), but there is a small residual AVM (anteroposterior $[D]$ and lateral $[E]$ views at the median arterial phase) with drainage via a cortical vein ( $F$, white arrow) to the superior sagittal sinus, which appeared at the late arterial phase of DSA. Thirteen-month angiography follow-up confirms the complete occlusion of the residual AVM (anteroposterior [G] and lateral $[H]$ views at the median arterial phase and lateral view [I] at the late arterial phase).

\section{Procedural Safety}

Procedure-related complications occurred in 6 patients, including 4 intraventricular hemorrhages, 1 intraparenchymal hemorrhage with combined intraventricular hemorrhage (Fig 3), and 1 cerebral infarction (Fig 4). Three of these patients underwent ventriculostomy, 1 of whom also underwent lumbar drainage; the other patients just had conservative management. Good outcomes $(\mathrm{mRS} \leq 2)$ at the 1 -month evaluation were achieved in 4 patients following the above therapies. The clinical outcome was poor $(\mathrm{mRS}=5)$ in 1 patient (Fig 4$)$ at the 1 -month evaluation, and another patient died.

Among the above complications, 5 occurred in small-sized AVMs, 5 in eloquent areas, 5 with deep venous drainage, 9 in deep locations, 4 with Spetzler-Martin III, 4 with aneurysms in the feeding artery or AVM nidus, and 1 with venous outflow stenosis. The Fisher exact test indicated no significant difference among these factors (Table 3).

The mRS scores at the latest follow-up for all surviving patients were as follows: 0 for 15 patients, 1 for 2 patients, 2 for 2 patients, and 5 for 1 patient. The percentage of good outcome
$(\mathrm{mRS} \leq 2)$ increased from $57.1 \%(12 / 21)$ before embolization to $66.7 \%(14 / 21)$ at 1 -month follow-up and $100 \%(19 / 19)$ at 6 month follow-up, respectively (Fig 5).

\section{DISCUSSION}

\section{Transvenous Obliteration}

Total occlusion of AVMs with detachable or nondetachable microcatheters in transarterial procedures is difficult to achieve, mostly due to a variety of challenges, including microcatheter navigation, multiplicity of arterial feeders, and achieving deep and complete Onyx penetration of the AVM nidus. ${ }^{5}$ In these challenging situations, transvenous embolization may be a viable alternative with total occlusion rates as high as $92.6 \%,{ }^{21}$ which is comparable with ours in this study. Transvenous microcatheter navigation, which occurred in 2 of our cases, might be difficult. However, this issue might be resolved by balloon-assisted microcatheter navigation techniques $^{22}$ or hybrid surgical techniques. ${ }^{23,24}$

The high occlusion rates of AVMs may be due to the small, compact architecture, which is more easily penetrated. 


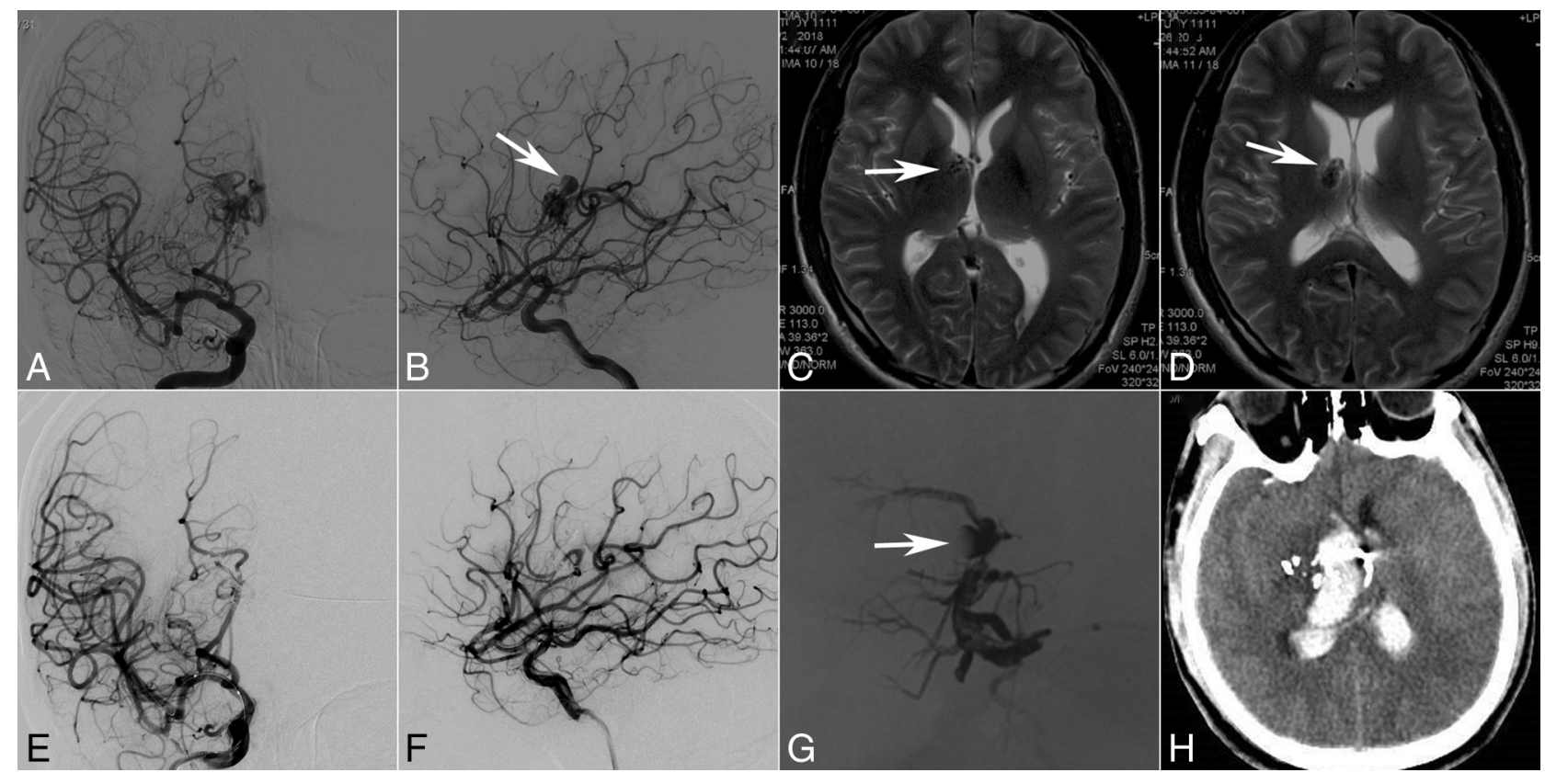

FIG 3. A 28-year-old man with intraventricular hemorrhage. Selective DSA of the right ICA (anteroposterior $[A]$ and lateral $[B]$ views) demonstrates that the AVM with an intranidal aneurysm (B, white arrow) is fed by perforators of the MCA and ICA and drains a single venous outlet via the deep vein to the straight sinus. Axial MR image indicates a basal ganglia arteriovenous malformation ( $C$, white arrow) with the intranidus aneurysm next to the ventricle $(D$, white arrow). At the end of the operation, the AVM does not appear at the last angiography (anteroposterior $[E]$ and lateral $[F]$ views), but the cast image shows that the aneurysm does not have complete penetration by the embolic agent (G, white arrow) after transarterial and transvenous embolization. Two days later, intraventricular hemorrhage occurred (H, CT).

Additionally, the single, embolized draining vein may, in turn, induce the occlusion of many shunts in the nidus. Because arteriovenous fistulas compose most brain AVMs with plexiform nidi and upstream shunts, arterial occlusion without obliteration of the venous drainage of brain AVMs can lead to recurrence. ${ }^{25}$ In the report of Viana et $\mathrm{al}^{26}{ }^{26}$ patient in whom immediate angiographic occlusion was not achieved showed spontaneous occlusion at the 6-month follow-up, ${ }^{26}$ which was also observed in this study.

Brain AVM-related events can be controlled once the AVM nidus has been obliterated. A case series demonstrated no events occurring in the 6-month follow-up in 11 patients. ${ }^{26}$ Another report indicated that only $1(2.5 \%)$ patient had significant disability at the 6-month follow-up, but unfortunately, no detailed information was provided. ${ }^{21}$ In this study, 1 seizure occurred 3 months after the operation.

\section{Procedural Safety}

Previous reports on the transvenous embolization of AVMs showed low rates of periprocedural complications, disability, and morbility. ${ }^{21,27}$ In contrast, the complication rate was relatively high in our study. There are several possible reasons: First, the present study enrolled only patients with ruptured AVMs (100\%), which had a higher risk for rebleeding. ${ }^{1}$ In the report of Mendes et $\mathrm{al}^{21}$ the rate of ruptured AVMs was only $67.5 \%$. Second, we enrolled more patients with higher Spetzler-Martin grades, and $66.7 \%$ of our patients were classified as Spetzler-Martin grade III or even higher. The percentage of higher Spetzler-Martin grades was $58.5 \%$ in the report of Mendes et $\mathrm{al}^{21}$ and only $25 \%$ in the report of Trivelato et al, ${ }^{11}$ which are architecturally more complex.

Infarctions caused during transvenous embolization are supposed to be related to either penetration of Onyx into the feeding artery of the normal brain tissue or hyperemia and edema caused by draining vein occlusion. The outcome may depend on the local collateral circulation. ${ }^{2,28}$ In this study, 1 cerebral infarct that caused disability was thought to be due to the occlusion of the feeding artery with Onyx. Trivelato et $\mathrm{al}^{11}$ and Mendes et $\mathrm{al}^{21}$ reported 2 cases each of postprocedural parenchymal edema thought to be related to venous outflow obstruction, one of which caused a disability.

Hemorrhagic complications might occur in different locations. Among the 5 hemorrhagic complications, 4 occurred in the eloquent area and 4 with deep venous drainage, which are also the risk factors for transarterial embolization. ${ }^{29}$ All 5 AVMs with hemorrhagic complications were located in deep brain structures and around ventricles and bled into the ventricles, which is not a usual complication of transarterial embolization. Periventricular location has been cited as a risk factor for hemorrhage. ${ }^{30}$ These hemorrhages may be related to the following reasons: ${ }^{18}$ high arterial input pressure and venous outflow restriction in the deep AVMs; not enough brain tissue around the ventricle; and a large pressure gradient between the nidus and ventricle. Premature occlusion of draining veins during transvenous embolization before complete occlusion of the nidus can increase the pressure in the 


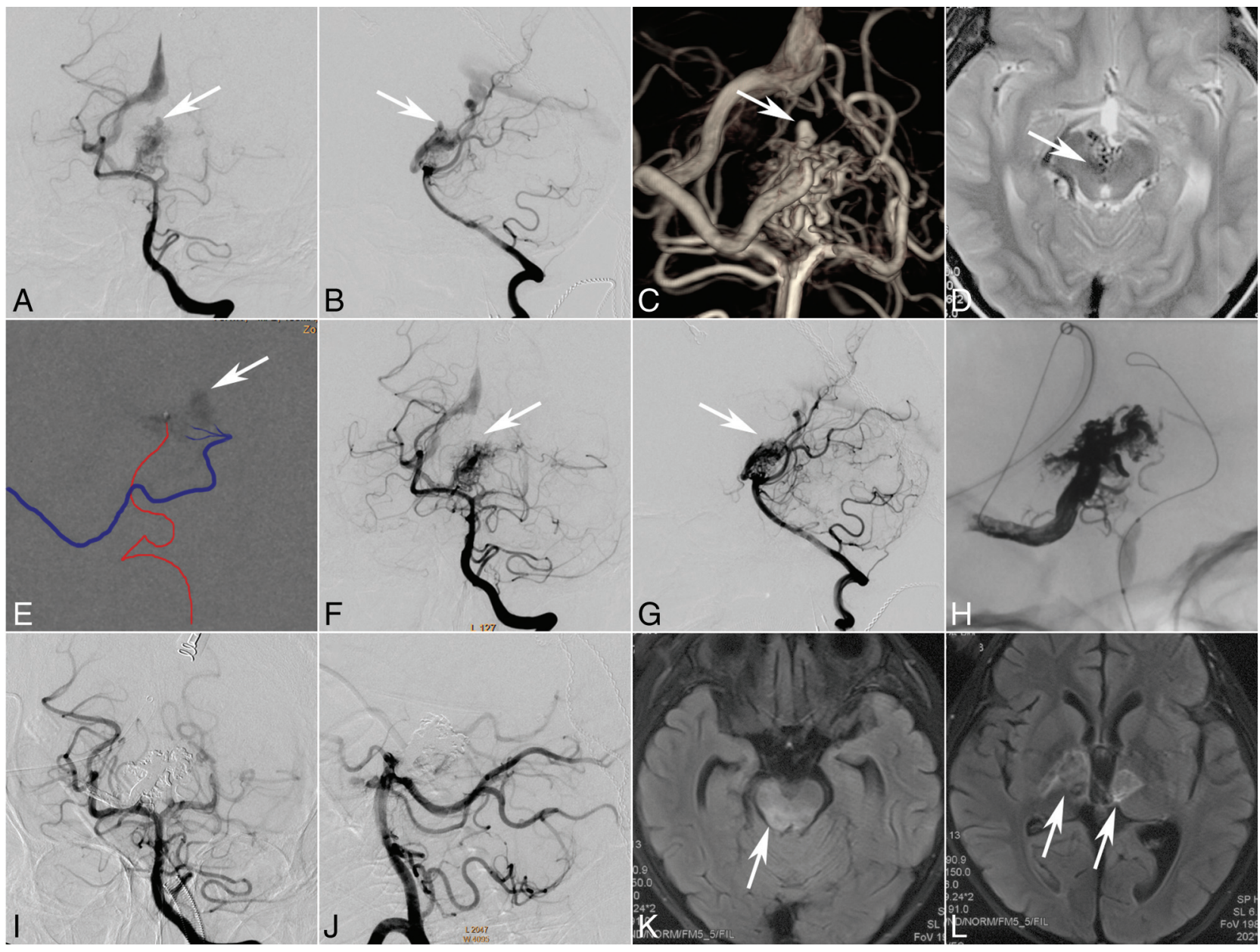

FIG 4. An 8-year-old boy who presented with sudden headache and vomiting. CT shows intraventricular hemorrhage. Selective DSA of the left vertebral artery (anteroposterior $[A]$ and lateral $[B]$ views, white arrow) demonstrates that the AVM with an intranidus aneurysm (C, 3D reconstruction, white arrow) is fed by the perforators of the posterior cerebral artery and drains a single venous outlet via the deep vein to the straight sinus. Axial MR image indicates a diencephalon arteriovenous malformation $(D$, white arrow). Transarterial ethanol sclerotherapy $(80 \%$ ethanol in iohexol, Omnipaque 300 [GE Healthcare, Piscataway, New Jersey]) was performed to occlude the aneurysm (E, white arrow, the injection course can be seen in the On-line Video). Both the immediate angiography after sclerotherapy and the 2-month follow-up angiography (anteroposterior [F] and lateral [G] views, white arrow) demonstrate occlusion of the aneurysm. At 2-month follow-up, transvenous embolization was performed under transarterial balloon blocking $(H)$. The last angiography (anteroposterior [I] and lateral [] views) shows complete occlusion of the AVM. The intraprocedure electroencephalography monitoring did not show an abnormality, but the patient presented with light coma or lethargy. The MR imaging performed 12 days after the operation shows multiple infarctions in the mesencephalon ( $K$, white arrow) and thalamus ( $L$, white arrows).

Table 3: Relative analysis for the complications in 19 patients with technically feasible AVMs

\begin{tabular}{lccc}
\hline \multirow{2}{*}{ Variable } & \multicolumn{2}{c}{ Complication } & \\
\cline { 2 - 3 } & + & - & $P$ Value \\
\hline $\begin{array}{l}\text { Spetzler-Martin grade } \\
\text { I-II }\end{array}$ & 1 & 5 & .801 \\
III & 4 & 6 & \\
IV-V & 1 & 2 & \\
Size & & & .141 \\
$\quad \leq 3 \mathrm{~cm}$ & 5 & 5 & \\
$\quad>3 \mathrm{~cm}$ & 1 & 8 & \\
Eloquent & & & \\
$\quad+$ & 5 & 8 & \\
$\quad-$ & 1 & 5 & .057 \\
$\begin{array}{l}\text { Deep venous drainage } \\
\quad+\end{array}$ & 5 & & \\
$\quad$ & 1 & 4 & \\
\hline
\end{tabular}

Note:-+ indicates yes; -, no.
AVM nidus, ${ }^{31}$ which has been reported as one of the main causes of hemorrhagic complications. ${ }^{32}$ Therefore, transvenous embolization is considered an "all-or-nothing" technique. In this study, $3 \mathrm{AVMs}$ had residual nidi postembolization, with hemorrhages occurring in 2. The 1 AVM with a residual that did not bleed had continued drainage through a cortical vein after the deep drainage vein had been occluded, which may explain the lack of hemorrhage postprocedure.

Most of the patients in this study with complications (4/6) had good outcomes after receiving appropriate treatment. For the ischemic complications, the outcome depends on the location and size of the infarction, especially whether it is in an eloquent area. In this study, the patient with infarction involving the midbrain and thalamus did not recover well. For the other 5 hemorrhagic complications, 4 


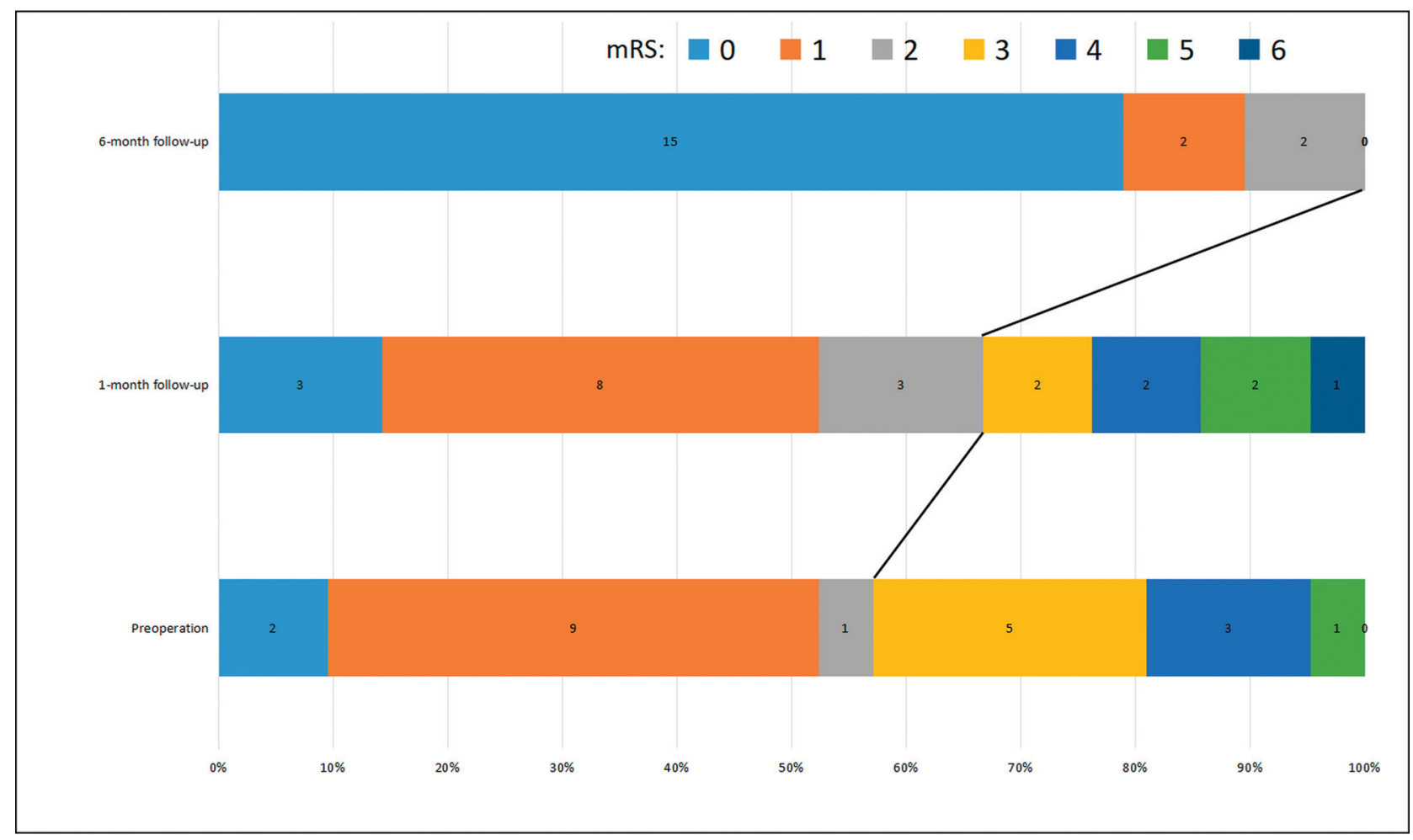

FIG 5. The good functional outcome (mRS $\leq 2$ ) ratios improved from $57.1 \%$ (12/21) before the operation to $66.7 \%$ (14/21) at 1-month follow-up and $100 \%(19 / 19)$ at 6-month follow-up, respectively.

patients had good outcomes and 1 died due to severe intracranial infection after hemorrhage. This might be related to several factors: First, intraparenchymal hemorrhage often occurs in the same area as prior hemorrhage and is less likely to immediately damage healthy brain; second, the subarachnoid hemorrhage can be treated by drugs or ventriculostomy; and finally, the patients were relatively young in this study.

\section{Limitations}

Although the number of cases in this study was the second largest in all the publications currently available, ${ }^{21}$ the sample size was still small. The patients were carefully selected and were selected for salvage procedures due to lack of good microsurgical, transarterial, and radiosurgical options, which may imply greater propensity for procedural risk than in other studies. Treatment strategy, patient factors, and doctors' experience are highly individualized and variable worldwide; thus, the findings of our study may not be consistent with other centers.

\section{CONCLUSIONS}

Transvenous embolization with high complete obliteration rates, improved functional outcomes, and acceptable morbidity and mortality rates can be performed in only carefully selected brain AVMs. However, more experience is necessary to discern the role of this technique in the management of ruptured AVMs, and it should not be considered a first-line treatment.

\section{ACKNOWLEDGMENTS}

The authors thank Yanyan He, Bin Xu, Xiaoyu Kang at Henan Provincial People's Hospital for data collection; Jingge Zhao at Henan Provincial People's Hospital for statistical analyses; Ajmal Zemmar and Juha Hernesniemi at Henan Provincial People's Hospital for their English editing assistance; and David F. Kallmes, Ramanathan Kadirvel, Daying Dai, and Kimberly Collins at the Mayo Clinic for their help in providing learning office and reference material.

\section{REFERENCES}

1. Solomon RA, Connolly EJ. Arteriovenous malformations of the brain. N Engl J Med 2017;376:1859-66 CrossRef Medline

2. Chen W, Choi EJ, McDougall CM, et al. Brain arteriovenous malformation modeling, pathogenesis, and novel therapeutic targets. Transl Stroke Res 2014;5:316-29 CrossRef Medline

3. Derdeyn CP, Zipfel GJ, Albuquerque FC, et al; American Heart Association Stroke Council. Management of Brain Arteriovenous Malformations: a Scientific Statement for Healthcare Professionals from the American Heart Association/American Stroke Association. Stroke 2017;48:e200-24 CrossRef Medline

4. Cenzato M, Boccardi E, Beghi E, et al. European consensus conference on unruptured brain AVMs treatment (supported by EANS, ESMINT, EGKS, and SINCH). Acta Neurochir (Wien) 2017;159:1059-64 CrossRef Medline

5. Elsenousi A, Aletich VA, Alaraj A. Neurological outcomes and cure rates of embolization of brain arteriovenous malformations with 
n-butyl cyanoacrylate or Onyx: a meta-analysis. J Neurointerv Surg 2016;8:265-72 CrossRef Medline

6. Nguyen TN, Chin LS, Souza R, et al. Transvenous embolization of a ruptured cerebral arteriovenous malformation with en-passage arterial supply: initial case report. J Neurointerv Surg 2010;2:150-52 CrossRef Medline

7. Kessler I, Riva R, Ruggiero M, et al. Successful transvenous embolization of brain arteriovenous malformations using Onyx in five consecutive patients. Neurosurgery 2011;69:184-93; discussion 193 CrossRef Medline

8. Pereira VM, Marcos-Gonzalez A, Radovanovic I, et al. Transvenous embolization of a ruptured deep cerebral arteriovenous malformation: a technical note. Interv Neuroradiol 2013;19:27-34 CrossRef Medline

9. Consoli A, Renieri L, Nappini S, et al. Endovascular treatment of deep hemorrhagic brain arteriovenous malformations with transvenous Onyx embolization. AJNR Am J Neuroradiol 2013;34:180511 CrossRef Medline

10. Ahmed AZ. Endovascular venous approach in the treatment of ruptured intra-cerebral arterio-venous malformation. The Egyptian Journal of Radiology and Nuclear Medicine 2014;45:439-41 CrossRef

11. Trivelato FP, Manzato LB, Rezende MT, et al. Transitory brain stem edema following successfully transvenous embolization of a posterior fossa arteriovenous malformation. Clin Neuroradiol 2014; 24:151-53 CrossRef Medline

12. Choudhri O, Ivan ME, Lawton MT. Transvenous approach to intracranial arteriovenous malformations: challenging the axioms of arteriovenous malformation therapy? Neurosurgery 2015;77:644-52 CrossRef Medline

13. Renieri L, Limbucci N, Consoli A, et al. Transvenous embolization: a report of 4 pediatric cases. J Neurosurg Pediatr 2015;15:445-50 CrossRef Medline

14. Iosif C, Mendes GA, Saleme S, et al. Endovascular transvenous cure for ruptured brain arteriovenous malformations in complex cases with high Spetzler-Martin grades. J Neurosurg 2015;122:1229-38 CrossRef Medline

15. Lawton MT; UCSF Brain Arteriovenous Malformation Study Project. Spetzler-Martin Grade III arteriovenous malformations: surgical results and a modification of the grading scale. Neurosurgery 2003;52:740-49 CrossRef Medline

16. Pollock BE, Flickinger JC. A proposed radiosurgery-based grading system for arteriovenous malformations. J Neurosurg 2002;96:7985 CrossRef Medline

17. Zhang G, Zhu S, Wu P, et al. The transvenous pressure cooker technique: a treatment for brain arteriovenous malformations. Interv Neuroradiol 2017;23:194-99 CrossRef Medline

18. He Y, Bai W, Li T, et al. Curative transvenous embolization for ruptured brain arteriovenous malformations: a single-center experience from China. World Neurosurg 2018;116:e421-28 CrossRef Medline
19. Chapot R, Stracke P, Velasco A, et al. The pressure cooker technique for the treatment of brain AVMs. J Neuroradiol 2014;41:87-91 CrossRef Medline

20. Jayaraman MV, Meyers PM, Derdeyn CP, et al. Reporting standards for angiographic evaluation and endovascular treatment of cerebral arteriovenous malformations. J NeuroIntervent Surg 2012;4:325-30 CrossRef Medline

21. Mendes G, Kalani M, Iosif C, et al. Transvenous curative embolization of cerebral arteriovenous malformations: a prospective cohort study. Neurosurgery 2018;83:957-64 CrossRef Medline

22. Mendes GA, Silveira EP, Saleme S, et al. Balloon-assisted microcatheter navigation for AVM embolization: technical note. J Neurosurg 2015;123:1120-24 CrossRef Medline

23. Wang MZ, Qiu HC, Wang S, et al. A new technique for transvenous embolization of brain arteriovenous malformations in hybrid operation. Chin Med J (Engl) 2018;131:2993-96 CrossRef Medline

24. Kulcsar Z, Machi P, Schaller K, et al. Trans-venous embolization of a basal ganglia ruptured arteriovenous malformation with open surgical arterial control: a hybrid technique. J Neuroradiol 2018;45:202-05 CrossRef Medline

25. Houdart E, Gobin YP, Casasco A, et al. A proposed angiographic classification of intracranial arteriovenous fistulae and malformations. Neuroradiology 1993;35:381-85 CrossRef Medline

26. Viana DC, de Castro-Afonso LH, Nakiri GS, et al. Extending the indications for transvenous approach embolization for superficial brain arteriovenous malformations. J NeuroIntervent Surg 2017; 9:1053-59 CrossRef Medline

27. Lv X, Song C, He H, et al. Transvenous retrograde AVM embolization: indications, techniques, complications and outcomes. Interv Neuroradiol 2017;23:504-09 CrossRef Medline

28. Stüer C, Ikeda T, Stoffel M, et al. Evidence for a predominant intrinsic sympathetic control of cerebral blood flow alterations in an animal model of cerebral arteriovenous malformation. Transl Stroke Res 2010;1:210-19 CrossRef Medline

29. Pan J, He H, Feng L, et al. Angioarchitectural characteristics associated with complications of embolization in supratentorial brain arteriovenous malformation. AJNR Am J Neuroradiol 2014;35:35459 CrossRef Medline

30. Ma L, Huang Z, Chen XL, et al. Periventricular location as a risk factor for hemorrhage and severe clinical presentation in pediatric patients with untreated brain arteriovenous malformations. AJNR Am J Neuroradiol 2015;36:1550-57 CrossRef Medline

31. D'Aliberti G, Talamonti G, Piparo M, et al. Venous flow rearrangement after treatment of cerebral arteriovenous malformations: a novel approach to evaluate the risks of treatment. World Neurosurg 2014;82:160-69 CrossRef Medline

32. Baharvahdat $H$, Blanc R, Termechi R, et al. Hemorrhagic complications after endovascular treatment of cerebral arteriovenous malformations. AJNR Am J Neuroradiol 2014;35:978-83 CrossRef Medline 